\title{
Freeze-fracture Observations of the Cell Walls and Peribacillary Substances of Various Mycobacteria
}

\author{
By K. TAKEO, ${ }^{1 *}$ KAZUKO KIMURA, ${ }^{2}$ F. KUZE, ${ }^{3}$ E. NAKAI, ${ }^{+}$ \\ T. NONAKA, ${ }^{4}$ AND M. NISHIURA ${ }^{4}$ \\ ${ }^{1}$ Department of Antibiotics, Research Institute for Chemobiodynamics, Chiba University, \\ Inohana, Chiba 280, Japan \\ ${ }^{2}$ Department of Bacteriology and ${ }^{3}$ The First Department of Medicine, Chest Disease Research \\ Institute, Kyoto University, Kyoto 606, Japan \\ ${ }^{4}$ Leprosy Research Laboratory, Faculty of Medicine, Kyoto University, Kyoto 606, Japan
}

(Received 2 November 1983; revised 14 December 1983)

Ultrastructure of the cell wall and peribacillary substances of various mycobacteria ( 32 strains of 18 species) grown in vitro was studied by a freeze-fracture technique. Peribacillary substances differed in shape among species and even among strains of the same species, and were classified into five types: (1) amorphous substances; (2) multi-layered sheaths with no filamentous units; (3) structures composed of filaments of 2-4 nm diameter, which were further classified into three subtypes according to the arrangement of the filaments; (4) helical fibres; and (5) single fibres, or networks of fibrous structures, with no visible substructures. No strains revealed peribacillary structures resembling those of uncultivable Mycobacterium leprae. These results have implications for the mechanism of freeze-fracturing in mycobacterial walls.

\section{INTRODUCTION}

The ultrastructure of Mycobacterium has been studied extensively by thin sectioning, negative staining and scanning electron microscopy (for reviews, see Barksdale \& Kim, 1977; Draper, 1982). A few mycobacterial species, including the pathogenic ones $M$. avium, $M$. leprae and $M$. lepraemurium, have also been studied by the freeze-fracture technique. This technique has shown three-dimensional ultrastructure, especially the difference in shape between the peribacillary substances of $M$. leprae, which are composed of amorphous droplets, and those of $M$. lepraemurium and $M$. avium, which are composed of fine crystalline structures (Nishiura $e t$ al., 1972; Draper \& Rees, 1973; Draper, 1974; Nishiura et al., 1977).

We have studied several species of mycobacteria, grown under various conditions, by means of the freeze-fracture technique, seeking possible new peribacillary structures, since mycobacterial cell walls are known to have a high content of various lipids (for reviews, see Goren, 1972; Barksdale \& Kim, 1977; Minnikin, 1982), and fracture is expected to occur between hydrophobic bilayers of lipids (Branton, 1966). We also wished to know whether the peribacillary structures of $M$. leprae exist in cultivable species of mycobacteria.

\section{METHODS}

Organisms. Some of the Mycobacterium strains were stock cultures in our laboratories, others were obtained from the Institute for Fermentation, Osaka (IFO), Japan or were kindly supplied by Dr M. Tsukamura, Chubu National Sanatorium, Obu, Japan. The species and strain numbers according to the designation of IFO and Dr Tsukamura (T) are shown in Table 1, together with the strain number of the American Type Culture Collection, where possible, in parentheses.

Growth conditions. The organisms were usually grown on Ogawa-egg medium at $30^{\circ} \mathrm{C}$ or $37^{\circ} \mathrm{C}$ for $3 \mathrm{~d}$ to 4 weeks; $M$. xenopi was grown at $45^{\circ} \mathrm{C}$ for $4-5$ weeks. Some strains were additionally grown by standing in $\mathrm{Kirchner}$ medium, by shaking in Dubois $-0.4 \%(\mathrm{v} / \mathrm{v})$ Tween 80 liquid medium, or by standing or shaking in nutrient broth 
enriched with $4 \%(\mathrm{v} / \mathrm{v})$ glycerol, and/or on Bennet's agar, to see whether nutritional differences affected the peribacillary structures.

Preparation of samples and freeze-fracturing. Cultures were usually transferred directly to the specimen holder of the freeze-etching apparatus without any pretreatment. Immediately before freezing, $30 \%(\mathrm{v} / \mathrm{v})$ glycerol solution was added as a cryoprotectant and to produce a cell paste. Some cultures, especially those of the pathogenic species, were fixed with $2.5 \%(\mathrm{v} / \mathrm{v})$ glutaraldehyde in $0.07 \mathrm{M}$-phosphate buffer, $\mathrm{pH} 7 \cdot 2$, for a few days at room temperature or at $4{ }^{\circ} \mathrm{C}$. They were immersed before use in $30 \%(\mathrm{v} / \mathrm{v})$ glycerol containing the same buffer overnight at $4{ }^{\circ} \mathrm{C}$, and usually cooled from the room temperature of $10-20^{\circ} \mathrm{C}$ but sometimes from $0{ }^{\circ} \mathrm{C}$. Electron micrographs were printed in reverse contrast to facilitate interpretation.

\section{RESULTS}

\section{Localized peribacillary substances}

Freeze-fracture of the mycobacteria usually occurred near the wall surface (Figs 1-9) and revealed peribacillary structures. Regarding the location of the structures relating to the cell body, three kinds of structures were observed, depending on the species and strains, as follows: (i) localized structures; (ii) structures of rare occurrence or which may adhere to more than two cells; and (iii) layered structures which appear to cover the whole cell. Structures (i) and (ii) represent peribacillary substances and are described below. Structures of type (iii) may represent peribacillary or wall structures and will be described in the next section.

Peribacillary substances observed by freeze-fracturing or freeze-etching showed structural varieties among the various mycobacteria as follows. (1) Amorphous substances, clearly observed in the contour where two cells had been attached before fracturing (Fig. 1). (2) Multilayered sheaths with no filamentous units. This type was observed only in a few cells of $M$. fortuitum IFO 13159 and Mycobacterium sp. Nojima 1-3 (Fig. 2). Some of the sheaths encompassed two adjacent cells. (3) Structures composed of filaments $2-4 \mathrm{~nm}$ in diameter. These were further classified into three subtypes according to the arrangement of the filaments: (a) a few of the filaments ran parallel with each other to form a narrow sheet- or rod-like structure (Fig. 3); (b) parallel filaments appeared to pile up three-dimensionally (Fig. 4); they were abundant in $M$. marinum T 8010 grown in prolonged culture; (c) sheets, composed of the filamentous units, stacked into ribbon- or tape-like structures, mostly $50-100 \mathrm{~nm}$ in width but sometimes wider (Fig. 5); These were found in several mycobacteria, though they were thin and never covered the whole cell (Table 1). The filaments observed in $(a)$ and $(b)$ were thicker and further from each other than those in $(c)$. (4) Rodlets composed of helical fibres, which were found in $M$. avium IFO 3082 and M. marinum T 8010 (Fig. 3). (5) Single fibres, or networks of fibrous structures, with no visible substructure. Some of these were easily detached from the wall and were probably peribacillary substances, although they may have arisen from the wall layers. Therefore they will be described in detail in the next section. The occurrence of these features in various strains is summarized in Table 1.

The peribacillary substances differed in shape and amount among strains of the same species, and even among cells grown in the same slant. This fact obscured the interpretation of findings in different nutritional conditions. The peribacillary substances appeared to increase in amount with prolonged cultivation (compare Figs 3 and 4). Some of them appeared to be easily detachable from the wall (Kim et al., 1976; Takeo et al., 1978) because they were also observed apart from the cells (Fig. 2), and because they decreased in amount when the cells were freezefractured after treatment with glutaraldehyde and glycerol. Cooling of some of the mycobacteria from room temperature and from $0{ }^{\circ} \mathrm{C}$ did not cause appreciable differences in peribacillary structures. This may be partly because room temperature $\left(10-20^{\circ} \mathrm{C}\right)$ is already below the culture temperature of 37 or $30^{\circ} \mathrm{C}$.

\section{Wall and peribacillary layers}

All the mycobacteria studied fractured near the wall surface, which is unusual in Grampositive bacteria, and revealed layered structures of the wall or peribacillary substances. Uitrastructural features of these outer layers differed among species and even among strains of the same species. Some had thick layers, as revealed by the depth of the ridges, while others had 
Table 1. Shapes of peribacillary substances of various mycobacteria observed in the present study

All strains showed freeze-fracture near the wall surface, which is unusual in Gram-positive bacteria. All but M. abscessus showed a band structure (e.g. see Fig. 2).

\begin{tabular}{|c|c|c|c|c|c|}
\hline Species & Strain* & $\begin{array}{l}\text { Peribacillary } \\
\text { substances } \dagger\end{array}$ & Species & Strain* & $\begin{array}{l}\text { Peribacillary } \\
\text { substances } \dagger\end{array}$ \\
\hline M. abscessus & T 19977 & $1,5 \mathrm{~B}$ & M. parafortuitum & T $16001(19687)$ & 1 \\
\hline M. agri & T 90012 & $1,5 \mathrm{~A}$ & & T $16003(19688)$ & 1 \\
\hline M. aurum & T 15001 & 1 & M. phlei & IFO 13160 & $1,5 \mathrm{~A}$ \\
\hline M. avium & IFO 3082 & $1,4,5 \mathrm{~B}$ & M. scrofulaceum & $(19981)$ & $1,5 \mathrm{~A}$ \\
\hline & Kirchberg & 1 & M. smegmatis & T 17002 & $1,3 c$ \\
\hline M. bovis & Ravenel & 1 & & T $17027(14468)$ & $1,5 \mathrm{~A}$ \\
\hline $\begin{array}{l}\text { M. chelonei } \\
\text { subsp. chelonei }\end{array}$ & T $19009(19235)$ & $1,5 \mathrm{~B}$ & $M$. thermoresistible & $\begin{array}{l}\text { IFO } 3083 \\
\text { T } 1039(19527)\end{array}$ & $\begin{array}{l}1,5 \mathrm{D} \\
1,3 c, 5 \mathrm{~A}\end{array}$ \\
\hline M. fortuitum & $\begin{array}{l}\text { T } 18112(6841) \\
\text { T } 18109(6842) \\
\text { IFO } 13159\end{array}$ & $\begin{array}{l}1,3 c \\
1,3 c \\
1,2\end{array}$ & M. tuberculosis & $\begin{array}{l}\text { H37Ra } \\
\text { Aoyama B } \\
\text { Kurono }\end{array}$ & $\begin{array}{l}1,5 \mathrm{~B} \\
1,5 \mathrm{~A}, \mathrm{~B} \\
1,5 \mathrm{~B}\end{array}$ \\
\hline M. gordonae & T $12109(14470)$ & 1 & M. xenopi & T $28001(19156)$ & 1 \\
\hline M. kansasii & $(12478)$ & $1,5 \mathrm{~A}$ & & T $28003(19250)$ & $1,5 \mathrm{~A}$ \\
\hline M. marinum & $\begin{array}{l}\text { T } 8010(927) \\
\text { T } 8002\end{array}$ & $\begin{array}{l}1,3 a, b, 4,5 \mathrm{~A} \\
1,3 b, 4\end{array}$ & Mycobacterium spp. & $\begin{array}{l}\text { Jucho } \\
\text { Nojima 1-3 }\end{array}$ & $\begin{array}{l}1,5 \mathrm{~A} \\
1,2,5 \mathrm{C}\end{array}$ \\
\hline$M$. nonchromogenicum & $\begin{array}{l}\text { T } 9003(19530) \\
\text { T } 9033(19533)\end{array}$ & $\begin{array}{l}1,3 c, 5 \mathrm{~A} \\
1,3 c\end{array}$ & & Nojima $4-2$ & 1 \\
\hline
\end{tabular}

* IFO, Institute for Fermentation, Osaka; T, Dr M. Tsukamura, Chubu National Sanatorium. ATCC numbers are shown in parentheses.

$\dagger$ The number signifies observation of the following structures (see also Figures): 1, amorphous substances; 2 , multi-layered sheaths with no filamentous units; 3 , structures composed of filamentous units $(a$, a few filaments running straight and parallel to each other to form a narrow sheet- or rod-like structure; $b$, filaments gathering three-dimensionally; and $c$, ribbon- or tape-like structures); 4 , helical fibres; 5 , single fibres or networks of fibrous structures with no visible substructures (A, wrinkled structures; B, short, straight fibres; C, parallel arrays of fibrils with gaps between each fibril; D, fibrils observed in $M$. smegmatis after repeated pipetting).

thin layers. The number of fracture planes was ascertained by the number of layers bounded by ridges in single walls. There were three fracture planes in $M$. phlei IFO 13160 (Fig. 6), $M$. smegmatis $\mathrm{T} 17027$ and $M$. gordonae T 12109 , indicating the existence of at least four layers in these organisms. There were one or two in the other strains, though this may be an underestimation of the number of fracturable planes. The exposed faces generally looked smooth.

In some walls, fibrous structures were observed. They showed structural variation but may be grouped into the following four types. (A) Wrinkled structures of 10-20 nm diameter (Fig. 7). They may be paired fibres or ropelike structures (Takeya et al., 1961; Barksdale \& Kim, 1977), or thick ramified fibres (Imaeda et al., 1968; Hawley et al., 1977). (B) Short, straight fibres of about $10 \mathrm{~nm}$ diameter (Fig. 8). (C) An array of parallel fibrils of about $4 \mathrm{~nm}$ diameter and separated by about $4 \mathrm{~nm}$, which appeared to cover the whole wall (Fig. 9). This array was observed only in Mycobacterium sp. Nojima 1-3. The fibrils ran parallel to the longer axis of the cell in about one third of the cells, but obliquely in the others. These features were more clearly observed in the E-face than the P-face. (D) M. smegmatis IFO 3083 showed several fibrils of about $5 \mathrm{~nm}$ diameter when grown in Dubois- $0.4 \%$ Tween medium with shaking, but not when grown on Ogawa-egg medium. Abundant fibrils were observed if $M$. smegmatis cells, grown on the Ogawa-egg medium, were suspended in the fixation solution by repeated use of a pipette (Fig. 10). It should be noted that areas with abundant fibrils gradually converted to areas having no fibrils and without ridges (Fig. 10). It remains to be resolved whether all these fibrous structures are different from each other, and whether they exist in the wall or the peribacillary layers. Some of them, e.g. those in Fig. 8, appear to show a structural resemblance to bacteriophages (Bradley, 1967).

Some polar regions in the wall showed a concentric-circular appearance (Fig. 11), which may correspond to that reported in Staphylococcus aureus as the newly exposed cell wall at division 

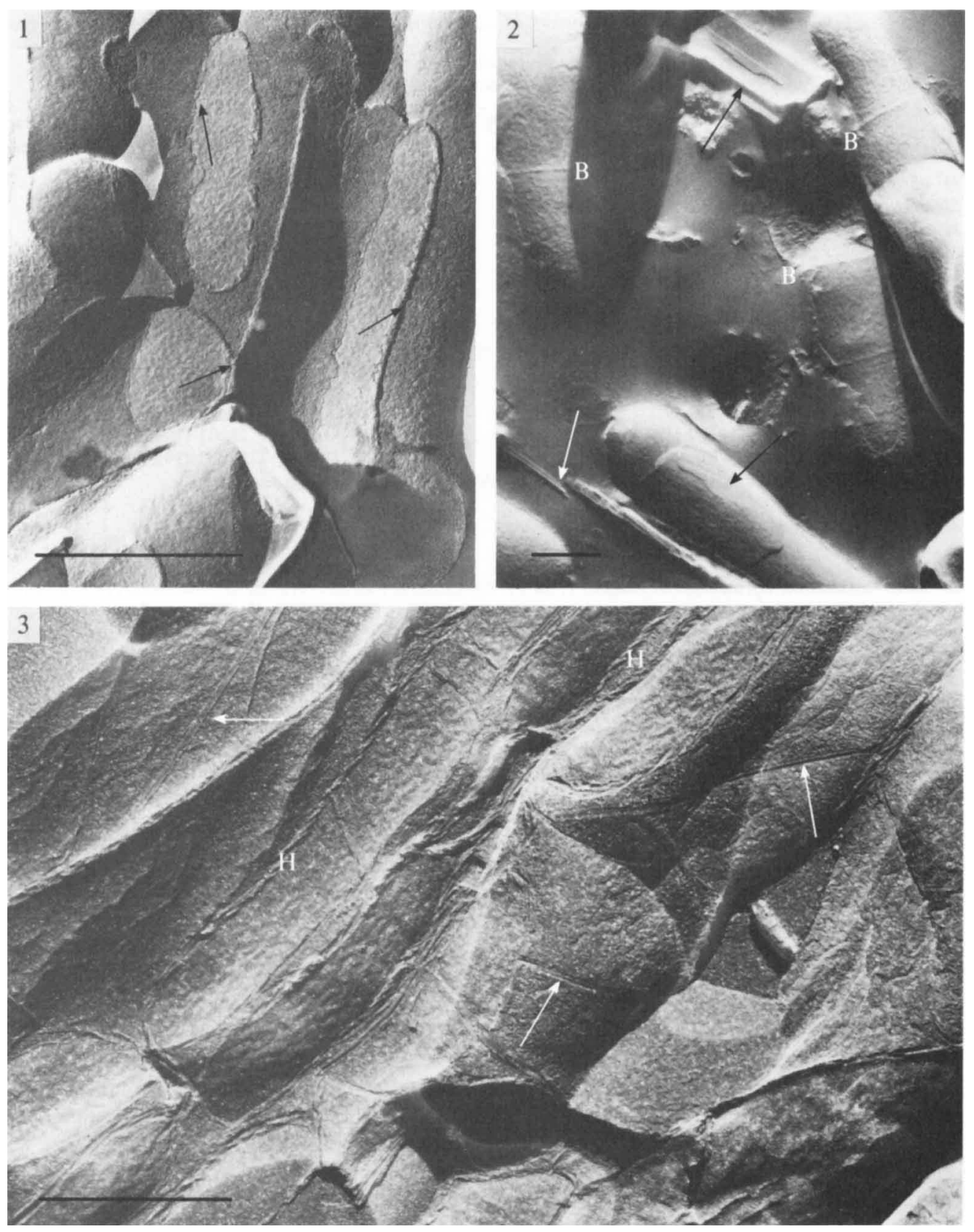

In all figures (1-11) cells were grown on Ogawa-egg medium and freeze-fractured without any pretreatment unless otherwise described. Bar markers represent $0.5 \mu \mathrm{m}$.

Fig. 1. Freeze-fractured $M$. fortuitum $\mathrm{T}$ 18112. Amorphous peribacillary substances (type 1) are thick at the boundary of the contact of the two cells (arrows).

Fig. 2. Freeze-etched $M$. fortuitum IFO 13159 after fixation and cryoprotection. Multilayered sheaths (type 2) are observed (arrows) both on the wall and apart from the cells. The latter were probably detached from the cells during sample preparation. See also band structures (B).

Fig. 3. Freeze-fractured M. marinum T 8010 after incubation for $12 \mathrm{~d}$ showing narrow sheet-or rod-like structures (type $3 a$ ) which are composed of filaments (arrows), and helical fibres (H) (type 4). 

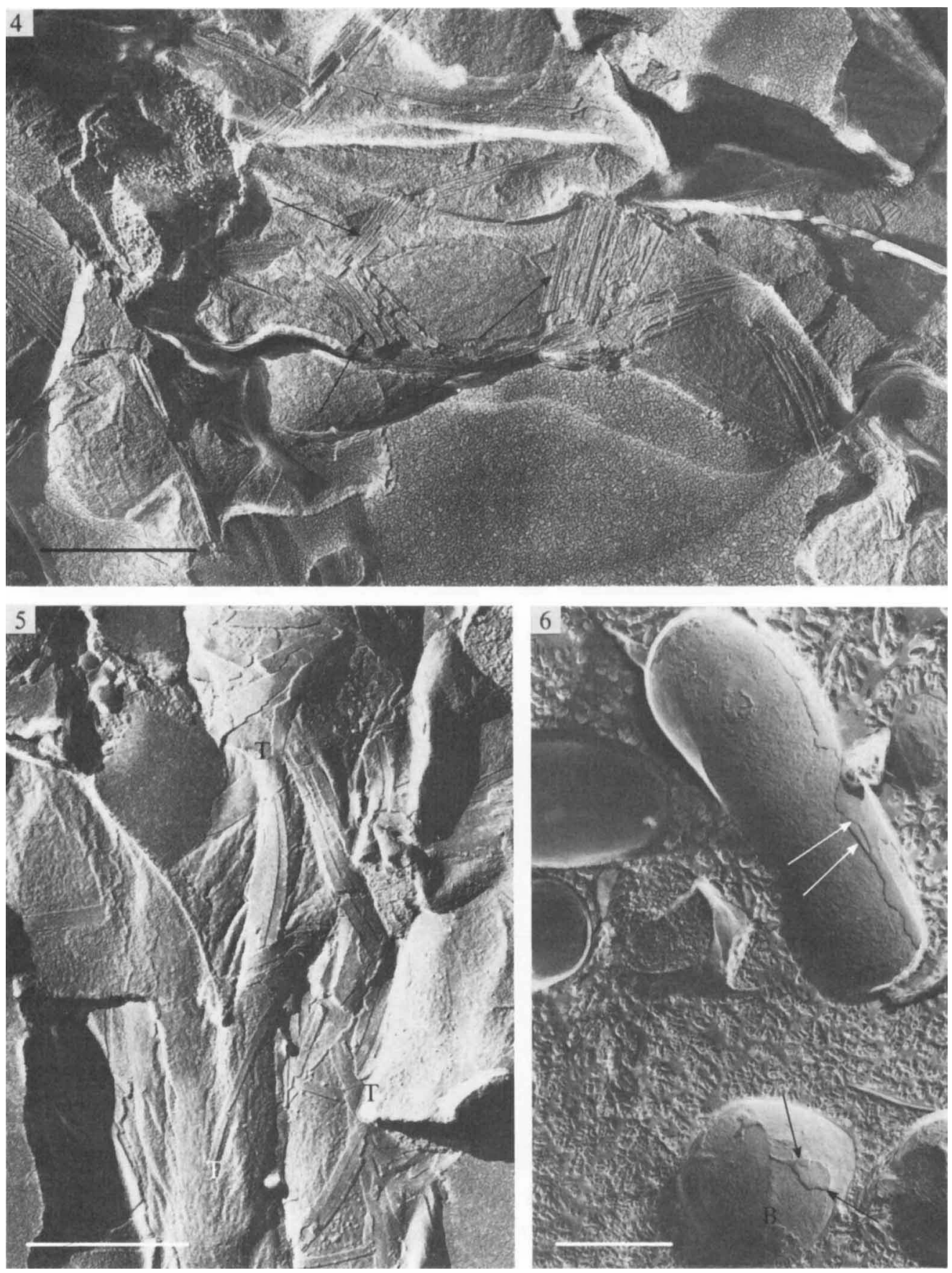

Fig. 4. Freeze-fractured $M$. marinum T 8010 from an old culture (about 2 months). Parallel filaments appear to pile up (type $3 b$ ) on some parts of the wall (arrows).

Fig. 5. Freeze-fractured $M$. nonchromogenicum T 9033 showing tape-like structures (type $3 c$ ) on the wall $(\mathrm{T})$.

Fig. 6. Freeze-etched $M$. phlei IFO 13160 after fixation and cryoprotection showing three fracture planes on the same cell (arrows). See also the band structure (B). 

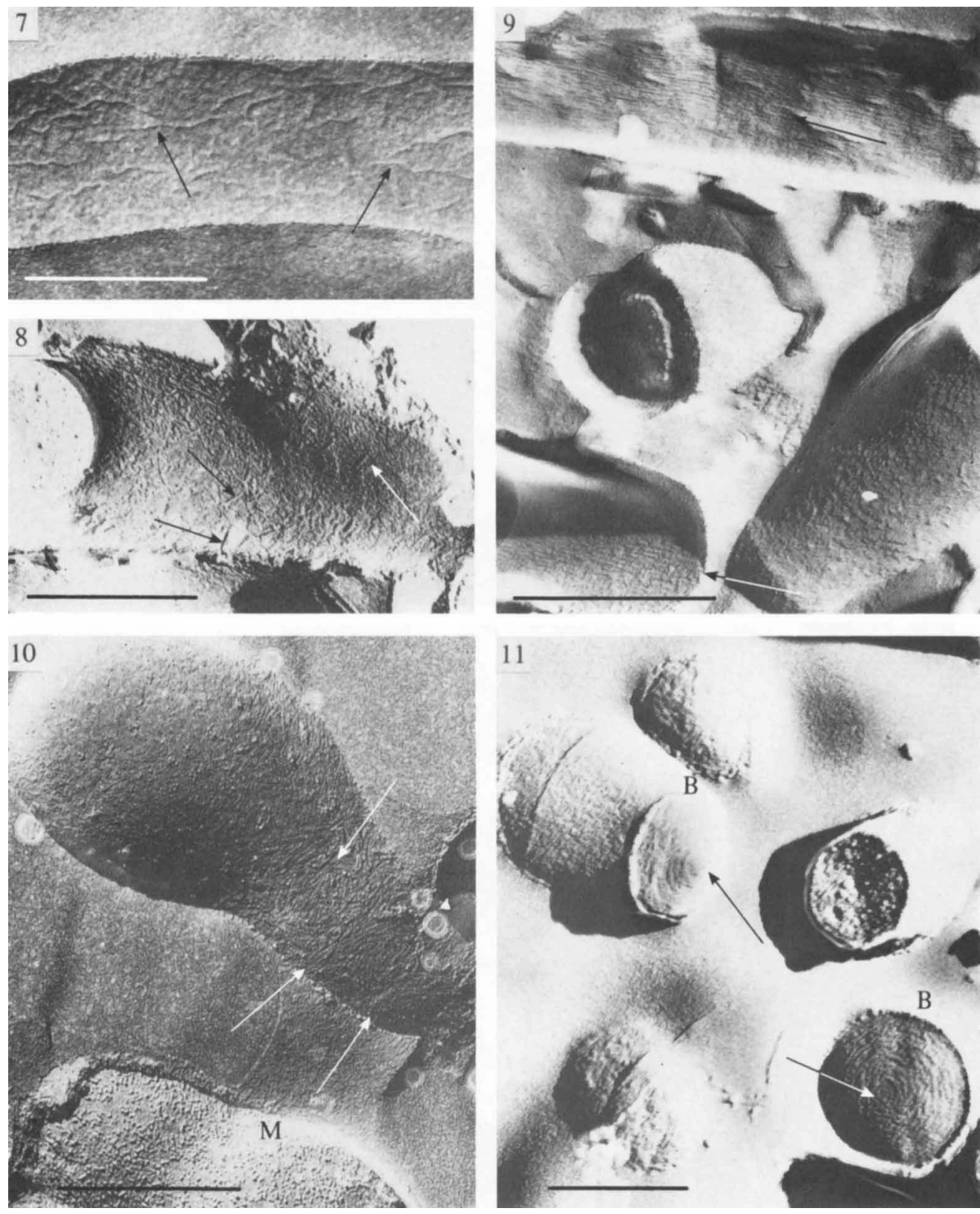

Fig. 7. Freeze-fractured $M$. thermoresistible T 1039 showing ropelike wrinkles (type 5A) (arrows).

Fig. 8. Freeze-fractured $M$. abscessus T 19977 showing short, straight fibres (type 5B) in the E-face (arrows).

Fig. 9. Freeze-fractured Mycobacterium sp. Nojima 1-3 showing long parallel fibrils with gaps between them (type 5C). Two arrays of the fibrils which run parallel to the long axis of the cell are shown in the Eface (arrows).

Fig. 10. Freeze-fractured $M$. smegmatis IFO 3083 showing fibrils (arrows) which are revealed when cells were freeze-fractured after repeated pipetting (type 5D). See also the P-face of the plasma membrane (M).

Fig. 11. Freeze-etched $M$. scrofulaceum ATCC 19981 showing a concentric-circular appearance of the wall in the polar area of the cell (arrows), which is surrounded by the band structure (B). 
(Giesbrecht \& Wecke, 1971; Amako et al., 1982). Surrounding the concentric-circular area of the wall, a band-like swelling of the wall about $20 \mathrm{~nm}$ wide and $20 \mathrm{~nm}$ high could usually be seen (Fig. 11). It has been suggested that this forms at the new cell pole at binary fission, because in cell pairs just after fission it appears at the new cell pole (Izumi et al., 1970). Our results for various mycobacteria confirmed this earlier observation, though only a few cells of $M$. thermoresistible, $M$. nonchromogenicum, $M$. marinum and $M$. xenopi showed the bands and none could be seen in $M$. abscessus. This fact indicates deterioration of bands or deposition of substances on the walls of these species. In contrast, the bands were usually seen in some strains of $M$. phlei, M. scrofulaceum, M. fortuitum and Mycobacterium sp. Nojima 1-3, showing that the bands are conserved for a few generations. In these organisms the bands serve as good natural markers to reveal the mode of growth, especially the localized wall growth of mycobacteria $(\mathrm{K}$. Takeo, unpublished), since they mark on the wall the places where cell divisions have occurred.

\section{DISCUSSION}

The crystalline form of a substance reflects its physicochemical properties. Some lipids are known naturally to form helices (see Tachibana \& Kambara, 1965). Mycobacterial peribacillary substances which take a helical shape (type 4) may be composed of such lipids. Multilayered sheaths (type 2) are reasoned to be composed of polar lipids in which polar and hydrophobic bilayers are stacked alternately (Moor \& Mühlethaler, 1963). C-mycosides are known to exist in $M$. avium, $M$. marinum (=M. scrofulaceum), $M$. butyricum and $M$. kansasii (for a review see Goren, 1972). They are serotype-specific substances of the $M$. avium-M. intracellulare- $M$. scrofulaceum complex (Brennan \& Goren, 1979) to which $M$. lepraemurium is closely related (Draper, 1974). Ribbon-like structures composed of C-mycosides have been reported in $M$. lepraemurium, M. avium and Mycobacterium sp. (Draper \& Rees, 1973; Draper, 1974; Kim et al., 1976). We found similar structures in some strains of $M$. fortuitum, $M$. nonchromogenicum, $M$. smegmatis and $M$. thermoresistible, though it is not certain whether all of them contain Cmycosides. In no strains were the sheets as thick as in M. lepraemurium (Draper \& Rees, 1973; Nishiura et al., 1977) nor did they cover the whole cell. The stacking of hydrophobic bilayers (where freeze-fracture occurs) in capsular form would hinder the exchange of hydrophilic metabolites, except for organisms growing very slowly, such as $M$. lepraemurium, though on the other hand, it appears to be a good protection against host defence mechanisms (Draper \& Rees, 1970).

Cultivation of $M$. leprae in vivo has been successful in armadillos and nude mice (Storrs et al., 1974; Kohsaka et al., 1976) though it has been complicated sometimes by naturally occurring or contaminating mycobacteria. Among the 32 strains of 18 species of cultivable mycobacteria that we studied, no strains revealed peribacillary structures resembling those of $M$. leprae, which may offer one basis to distinguish $M$. leprae ultrastructurally from natural or contaminating mycobacteria (Fukunishi et al., 1982).

Imaeda et al. (1968) proposed, on the basis of negative staining, that mycobacterial walls consisted of three layers. Freeze-fracturing and negative staining led Barksdale \& Kim (1977) to propose a four-layered model as follows: (smooth) sheetlike surface glycolipid or peptidoglycolipid $\left(\mathrm{L}_{1}\right)$; wrinkled and superficial $\left(\mathrm{L}_{2}\right)$; the underlying fibrous ropelike structure $\left(\mathrm{L}_{3}\right)$; and (smooth) innermost peptidoglycan. Draper (1982) has regarded the outer two layers in both models as capsule, not covalently bound to the wall. Our results support his view: outer layers of mycobacterial walls differed, even among strains of the same species, in the number of the fracture planes bounded by distinct ridges, in the ridge thickness of these layers and in the shape of structures found in these layers. We use the term 'peribacillary substances' because some structures exist only locally.

The freeze-fracture technique is useful for visualizing layered structure. There seems to be an implicit supposition that exposed faces showing an essential difference in appearance represent different layers or, in other words, that a certain face exposed by the fracture between certain layers always looks essentially the same. As suggested by the following four lines of reasoning, this may not be valid in mycobacterial walls, including peribacillary layers, unless they are split 
into improbably large numbers of layers. First, the high content of various kinds of lipids in mycobacterial walls (for reviews, see Goren, 1972; Barksdale \& Kim, 1977; Minnikin, 1982), which may reach $60 \%$ of the dry weight (Kotani et al., 1959), probably forms plenty of hydrophobic bonds. A group of hydrophobic substances which nearly cover a plane possibly offers one fracture plane. Thus, different walls may have different fracturable planes or even one wall may have different fracturable planes in a certain layer. In other words, certain double layers in mycobacterial walls may be split along visible structures in some cells but only along amorphous substances in others. Secondly, different layers in the model of Barksdale \& Kim are wrinkled to different extents as described above. However, it is unlikely that the two exposed faces (the E-face of the upper layer and the P-face of the underlying layer) were in full contact by hydrophobic bonds before fracturing. This conflict can be resolved if some layers which have wrinkled structures also have amorphous substances, and if they fracture in some cells along the wrinkled structures, revealing wrinkled faces, both in the E- and P-faces, but fracture in others only along amorphous substances, revealing smooth faces, as discussed above. Thirdly, single walls of $M$. phlei IFO 13160 revealed three fracture planes separated by ridges (Fig. 6), all of which were usually smooth, although sometimes ropelike wrinkles were observed. These facts suggest changes of the fracture path in wrinkled layers, though they may simply imply the existence of four smooth layers and in addition some wrinkled layers in $M$. phlei. Lastly, $M$. smegmatis IFO 3083 revealed plenty of fibrils in the wall (Fig. 10) when grown on Ogawa-egg medium and freeze-fractured after repeated pipetting, while it revealed few fibrils when this procedure was not used. Furthermore, areas with plenty of fibrils gradually changed to areas having no fibrils, without showing any ridges between them (Fig. 10). If these two different areas belong to two different layers of the wall, there should be a ridge in the transition areas. These facts appear to show that the fibrils may or may not be revealed due to subtle changes in the arrangement of the wall matrix and in the fracture pathway. Thus, it is suggested that exposed faces showing differences in appearance do not necessarily represent different layers in organisms whose envelopes are rich in hydrophobic substances.

\section{REFERENCES}

Amako, K., Umeda, A. \& Murata, K. (1982). Arrangement of peptidoglycan in the cell wall of Staphylococcus spp. Journal of Bacteriology 150, 844850.

BARKSDALE, L. \& KIM, K-S. (1977). Mycobacterium. Bacteriological Reviews 41, 217-372.

BRADLEY, D. E. (1967). Ultrastructure of bacteriophages and bacteriocines. Bacteriological Reviews 31, 230-314.

Branton, D. (1966). Fracture faces of frozen membranes. Proceedings of the National Academy of Sciences of the United States of America 55, 10481056.

Brennan, P. J. \& Goren, M. B. (1979). Structural studies on the type-specific antigens and lipids of the Mycobacterium avium . Mycobacterium intracellulare Mycobacterium scrofulaceum serocomplex. Journal of Biological Chemistry 254, 4205-4211.

DRAPER, P. (1974). The mycoside capsule of Mycobacterium avium 357. Journal of General Microbiology 83, 431-433.

DRAPER, P. (1982). The anatomy of mycobacteria. In The Biology of Mycobacteria, vol. 1, pp. 9-52. Edited by C. Ratledge \& J. Stanford. London: Academic Press.

DRAPER, P. \& REES, R. J. W. (1970). Electron-transparent zone of mycobacteria may be a defence mechanism. Nature, London 228, 860-861.
DraPer, P. \& ReEs, R. J. W. (1973). The nature of the electron-transparent zone that surrounds Mycobacterium lepraemurium inside the host cells. Journal of General Microbiology 77, 79-87.

Fukunishi, Y., OKada, S., Nishiura, M. \& Kohsaka, K. (1982). Ultrastructural features of the multiplication of human and murine leprosy bacilli in macrophages of nude mice. International Journal of Leprosy 50, 68-75.

GIESBRECHT, P. \& WeCKE, J. (1971). Zur Morphogenese der Zellwand von Staphylokokken. I. Querwandbildung und Zelltrennung. Cytobiologie 4, 349368.

GOREN, M. B. (1972). Mycobacterial lipids: selected topics. Bacteriological Reviews 36, 33-64.

Hawley, R. J., ManN, N. \& Imaeda, T. (1977). Ultrastructure of Nocardia-like variants of Mycobacterium smegmatis and chemical composition of the basal cell wall layer. Canadian Journal of Microbio$\log y$ 23, 1723-1732.

Imaeda, T., Kanetsuna, F. \& Galindo, B. (1968). Ultrastructure of cell walls of genus Mycobacterium. Journal of Ultrastructure Research 25, 46-63.

IzUMI, S., Nishiura, M., SUGIMORI, M., OKaDA, S. \& TAKIZAWA, H. (1970). A method of classifying solid leprosy bacilli based on the number of band structures on them. International Journal of Leprosy 38, 126-133. 
Kim, K-S., SALton, M. R. J. \& Barksdale, L. (1976). Ultrastructure of superficial mycosidic integuments of Mycobacterium sp. Journal of Bacteriology 125, 739-743.

KoHSAKa, K., Mori, T. \& ITo, T. (1976). Lepromatoid lesion developed in nude mouse inoculated with Mycobacterium leprae. - Animal transmission of leprosy. Lepro 45, 177-187.

Kotani, S., Kitaura, T., Hirano, T. \& Tanaka, A. (1959). Isolation and chemical composition of the cell walls of BCG. Biken Journal 2, 129-141.

MinNikin, D. E. (1982). Lipids: complex lipids, their chemistry, biosynthesis and roles. In The Biology of Mycobacteria, vol. 1. pp. 95-184. Edited by C. Ratledge \& J. Stanford. London: Academic Press.

MOOR, H. \& MüHLETHALER, K. (1963). Fine structure in frozen-etched yeast cells. Journal of Cell Biology 17, 609-629.

Nishiura, M., Uehira, K., Hasegawa, T. \& TAKEUCHI, M. (1972). The morphological difference between human and murine leprosy bacilli as revealed by the freeze-etching technique. International Journal of Leprosy 40, 89-90.
Nishiura, M., Izumi, S., Mori, T. \& Nonaka, T. (1977). Freeze-etching study of human and murine leprosy bacilli. International Journal of Leprosy 45 , 248-254.

Storrs, E. E., Walsh, G. P., Burchfield, H. P. \& BINFORD, C. H. (1974). Leprosy in the armadillo: new model for biochemical research. Science 183, 851-852.

TaChibana, T. \& Kambara, H. (1965). Enantiomorphism in the helical aggregate of lithium 12hydroxystearate. Journal of the American Chemical Society 87, 3015-3016.

TAKeo, K., Yamagishi, E., OKada, Y., KimUra, K. \& UESAKA, I. (1978). Ultrastructural changes of some mycobacterial walls after mild physical treatments: an example of the advantage of freeze-etching technique. Journal of Electron Microscopy 27, 237239.

TAKeya, K., MoRI, R., Tokunaga, T, KoIke, M. \& Hisatsune, K. (1961). Further studies on the paired fibrous structure of mycobacterial cell wall. Journal of Biophysical and Biochemical Cytology 9, 496-501. 